\title{
Programa Bolsa Família, mercado de trabalho e agência de mulheres titulares do Coque (Recife-PE)*
}

\author{
Giselle Nanes** \\ Marion Teodósio de Quadros***
}

\begin{abstract}
Resumo
Trata-se de uma pesquisa antropológica sobre titulares do Programa Bolsa Família (PBF), refletindo sobre a ampliação de direitos humanos das mulheres, um tema menos priorizado apesar de a titularidade feminina ser preferencial para o programa. Analisamos repercussões dessa titularidade nas trajetórias produtivas de 12 mulheres, residentes no Coque. Descrevemos aspectos importantes das trajetórias produtivas, marcadas por trabalhos informais, vexatórios e degradantes. Depois, relacionamos passagens dessas trajetórias ligadas a momentos anteriores e posteriores ao ingresso no $\mathrm{PBF}$, bem como exemplos de agência e autonomia realizados por elas, refletindo sobre processos de empoderamento. Finalmente, argumentamos que poderia existir maior potencialidade para $\mathrm{o}$ processo de autonomia na esfera produtiva e consequente saída do programa, se fosse efetivada a integração com políticas de trabalho $e$ renda que contemplem seus projetos de vida. Concluímos que a inserção no PBF não acomoda as mulheres na busca por trabalho, desmistificando o discurso do efeito preguiça.
\end{abstract}

Palauras-chave: Programa Bolsa Família, Titularidade Feminina, Gênero e Desenvolvimento, Trabalho, Autonomia, Empoderamento.

" Recebido em 16 de janeiro de 2018, aceito em 03 de julho de 2018.

*** Professora Adjunta do Departamento de Educação da Universidade Federal Rural de Pernambuco (UFRPE), Recife, PE, Brasil. Gisellenanes.2@gmail.com / ORCID 0000-0002-5264-8103

*** Professora Associada do Departamento de Antropologia e Museologia e do Programa de Pós-Graduação em Antropologia da Universidade Federal de Pernambuco (UFPE), Recife, PE, Brasil. marionteodosio@yahoo.com / ORCID 0000-0002-1123-0923 
Bolsa Família Program, Job Market and Women Recipient Agency in Coque (Recife-PE)

\begin{abstract}
This is an anthropological research about the Bolsa Familia Program (PBF) recipients, reflecting on the increase of women's human rights, a less prioritized subject despite the fact that women are the preferred recipients. We analyze repercussions of receiving $\mathrm{BF}$ in the productive trajectories of 12 women living in Coque. We describe their productive trajectories, marked by informal, vexatious and degrading jobs. Then, we relate passages of these trajectories linked to moments before and after joining the PBF, as well as examples of agency and autonomy performed by them, reflecting on empowerment processes. Finally, we argue that there could be greater potential for the process of autonomy in the productive sphere and consequent exit from the program, if integration with labor and income policies that address their life projects were effected. We conclude that the inclusion in the PBF does not make women drop or slow doen their search for work, demystifying the lazyness effect discourse.
\end{abstract}

Keywords: Bolsa Família Program, Women Holders, Gender and Development, Work, Autonomy, Empowerment. 


\section{Introdução}

Este artigo busca compreender as repercussões socioculturais da titularidade feminina dentro do Programa Bolsa Família (PBF), a partir de trajetórias de trabalho, vida familiar e reprodutiva de 12 mulheres beneficiárias. ${ }^{1}$

Em uma década de implementação do PBF (2003-2013) vários estudos foram realizados, especialmente nas áreas da Economia e do Serviço Social, com debate minoritário sobre a titularidade feminina e configurações de gênero (Nanes, 2014). A importância das reflexões em torno das questões de gênero $e$ titularidade merece destaque, mesmo que o programa não tenha sido concebido ou implementado como uma política de gênero.

No campo das ciências sociais, poucos trabalhos refletem sobre as experiências das mulheres que participam do programa ou discutem a titularidade feminina. Os temas abordados debatem repercussões morais e políticas na cidadania feminina, a partir da renda monetária (Suarez; Libardoni, 2007; Rego, 2008; 2010; Rego, Pinzani, 2013a; 2013b; Tebet, 2012), incentivos do PBF ao ingresso/permanência das mulheres no mercado de trabalho (Sorj; Fontes, 2010); PBF como política de redistribuição $e$ reconhecimento, com repercussão na simbologia do direito a ter direitos entre as mulheres titulares (Rabelo, 2013).

A normativa que regulamenta o PBF preconiza o estímulo das/dos beneficiárias/beneficiários a capacitação ou qualificação profissional, a partir de parcerias com políticas e programas de incentivo ao trabalho dentro dos municípios. O Ministério de Desenvolvimento Social e Combate à Fome estabelece que cabe aos municípios comprometer-se com o estabelecimento de parcerias com órgãos $e$ instituições municipais, estaduais $e$ federais, governamentais e não governamentais, para a oferta de

1 Trata-se de um recorte da pesquisa de Doutorado em Antropologia de Giselle Nanes, cuja tese intitula-se "Gênero, Desenvolvimento e Programa Bolsa Família: direitos reprodutivos, trabalho e projetos de vida de mulheres do Coque (Recife/PE)" (Nanes, 2014), orientada pela Professora Marion Teodósio de Quadros. 
programas complementares aos beneficiários do Programa Bolsa Família, especialmente ações de alfabetização, de capacitação profissional e de geração de emprego e renda desenvolvidos na sua esfera de competência (Brasil, 2005).

Tais parcerias, portanto, deveriam assumir importância capital no PBF, na medida em que significam a possibilidade real de rompimento do ciclo da pobreza intergeracional, já que apenas o repasse de transferência de renda, se constitui como um aporte temporário para essas famílias. Além disso, o baixo valor monetário do benefício se relaciona com a sobrevivência imediata da família, não potencializando a efetiva saída da pobreza.

Estudos demográficos e surveys (Sorj; Fontes; Machado, 2007; Lavinas; Cobo, Veiga, 2012) apontaram limitações do programa na promoção da autonomia feminina relacionada ao aumento da qualificação $e$ da melhoria das oportunidades de trabalho remunerado, na medida em que as parcerias com os municípios não se efetivam ou não têm estimulado a inserção/qualificação produtiva das beneficiárias.

Apesar dessa ausência e/ou ineficiência de ações específicas para inserção/qualificação profissional das mulheres titulares $e$ implicações para o empoderamento feminino, ao analisar o percurso de participação no programa e trajetórias produtivas das entrevistadas, observamos que elas formulam estratégias de agência que produzem, em alguma medida, sinais de autonomia por meio de escolhas relacionadas ao mercado de trabalho.

Articulados ao debate sobre gênero e desenvolvimento, utilizamos indicadores analíticos pouco visibilizados nas avaliações do programa e que constituem pontos nodais da discussão feminista: (i) direitos reprodutivos e maternidade; (ii) inserção/qualificação produtiva, estratégias de agência e processos de autonomia/empoderamento e (iii) projetos de vida (relacionados com ampliação de escolhas para agência $e$ empoderamento feminino).

Apoiando-nos nesses indicadores de avaliação do processo de empoderamento, nos referendamos no trabalho de Naila Kabeer $(1999 ; 2005)$ que inter-relaciona três dimensões analíticas 
[recursos (pré-condições); agência (processos) e realizações (resultados) $]^{2}$ e refletimos sobre relações entre recebimento de renda monetária, inserção na esfera produtiva, conciliação com o ciclo de vida familiar e processo de empoderamento feminino.

Consideramos que tais indicadores podem ampliar compreensão que interliga a titularidade feminina no PBF ao debate sobre políticas de desenvolvimento, pobreza e processos de autonomia/empoderamento feminino. A análise foi feita a partir da perspectiva da antropologia feminista (Moore, 2004), na qual as relações de família, parentesco, gênero e geração não podem desligar-se das relações econômicas e políticas. Especificamente neste artigo, colocamos em análise dados sobre as trajetórias na esfera produtiva, abordando relações observadas entre participação no mercado de trabalho, estratégias de agência $e$ processos de autonomia feminina entre titulares do programa.

A pesquisa etnográfica foi realizada entre 2012 e 2014, na comunidade do Coque, localizada na cidade do Recife (Pernambuco). A comunidade constitui uma zona especial de interesse social (ZEIS), considerando a situação de extrema pobreza das famílias e que historicamente são desprovidas de serviços básicos de infraestrutura básica de urbanização. De

2 Naila Kabeer (1999, 2003, 2005) aponta elementos para avaliação sobre empoderamento no campo de políticas de gênero e desenvolvimento. Argumenta que um das maneiras de pensar poder é em termos de habilidades de fazer escolhas. Empoderamento engloba processos de transformação que tangenciam possibilidades de fazer escolhas estratégicas por aqueles anteriormente negados e/ou proibidos dessa capacidade. O exercício dessas escolhas contempla três dimensões inter-relacionadas: recursos (pré-condições); agência (processos) e realizações (resultados). Os recursos vão além da ordem material e econômica, incluem recursos sociais, humanos e institucionais (família, comunidade, mercado de trabalho). A dimensão de agência engloba processos de barganha, negociação, manipulação, resistência e inteligibilidade, constituídos socioculturalmente. Realizaçóes concretizam-se a partir de mudanças e transformações ocorridas da conjunção de recursos e agência. Ressalta-se que as três dimensões, para Kabeer, englobam a compreensão do conceito de empoderamento, representando caminhos a partir dos quais ele se concretiza $e$ que estão intrinsecamente relacionados, de forma que transformações em uma dimensão podem levar alterações em outras (Kabeer, 1999, 2005). 
acordo com dados do Censo Demográfico (2010), a população do Coque é composta por cerca de 12.600 habitantes, com maior concentração nas faixas adulta $e$ infanto-juvenil (25-59 anos, 42\% e 5-14 anos, $22 \%$ da população). A proporção declarada de mulheres responsáveis por domicílio é de cerca de $57 \%$ e o valor de renda média mensal domiciliar é em torno de $\mathrm{R} \$ 700,00$.

Foram contatadas mais de 120 mulheres, das quais 12 foram selecionadas para que pudéssemos acompanhar suas convivências familiares, para obtenção de compreensão ampliada acerca da labuta feminina de mulheres pobres e das relações familiares compostas e vivenciadas dentro do contexto de participação no Programa Bolsa Família. Neste artigo, damos relevo aos relatos contidos nas entrevistas realizadas com essas interlocutoras, que estavam na faixa etária entre 20 e 30 anos, a maioria com ensino fundamental incompleto (com estudos até o $5^{\circ}$ ano) e mães de três a seis filhos. A principal fonte de renda familiar é a participação no Programa Bolsa Família (PBF), com valores do benefício que variam entre $R \$ 120,00$ e $R \$ 200,00$.

Para tanto, apresentamos descrição das trajetórias na esfera produtiva das mulheres pesquisadas, marcadas por trabalhos informais com remuneração irregular e/ou sub-remuneração. Em seguida, analisamos o enredamento dessas trajetórias com o percurso de inclusão no PBF e debatemos sobre possibilidades de autonomia na esfera produtiva, via empoderamento feminino.

Por fim, destacando a ausência e/ou ineficiência de propostas de formação e qualificação profissional dentro do PBF referentes à cidade de Recife, que viabilizem maior acesso aos postos de emprego formal, argumentamos que poderia existir maior potencialidade para o processo de autonomia na esfera produtiva (processo, como frisamos, mobilizado pelas próprias mulheres, no contexto da titularidade) e consequente saída do programa, se a sua formatação contemplasse propostas de qualificação profissional $e$ geração de renda para as mulheres pobres. 


\section{Trajetórias produtivas: relatos de mulheres titulares do Bolsa Família}

As trajetórias produtivas das mulheres acompanhadas na pesquisa são marcadas por trabalhos informais com remuneração irregulares e/ou sub-remuneração. Mencionam experiência em serviços domésticos (na ocupação de faxineira/diarista), trabalhos em bancas de jogo de bicho, localizadas na comunidade, ocupação de camareira em motéis e trabalhos como cozinheira ou auxiliar de serviços gerais em bares. Os relatos ${ }^{3}$ evidenciam (i) ocupações compreendidas como degradantes e vexatórias; (ii) trabalhos que colocam em risco a saúde física e psicológica das mulheres; e (iii) dificuldades de conciliação de inserção/permanência na esfera produtiva com o ciclo de vida familiar. A seguir, os relatos de Jurema, Joana, Diana e Joelma exemplificam casos de desrespeito a direitos trabalhistas, ausência de descanso remunerado, prejuízos à saúde das trabalhadoras, sofrimento de violência e humilhações no trabalho, no período anterior ao recebimento do benefício:

[Jurema, 28 anos]: No meu primeiro trabalho, eu cheguei a trabalhar num motel de camareira. Depois eu saí porque eu não aguentei por causa dos produtos de limpeza, que eram muito fortes, e eu tenho asma, tenho cansaço. O dono comprava só a essência e ele mesmo fazia, ficava muito forte. Eu cheguei a ficar doente [...] Eu nem tinha carteira assinada. Até hoje esse motel não assina carteira de nenhuma camareira. Junto tem outro motel, que é menor e assina carteira, mas esse dono não assina, é clandestino mesmo e para pagar, misericórdia, é uma demora.

[Joana, 29 anos]: Meu primeiro trabalho foi fazendo faxina, eram três dias na semana. Passei um bom tempo lá. Aí foi quando minha patroa chegou pra mim e disse que a babá ia sair, e queria que eu ficasse pra dormir, aí eu disse: "oh, doutora, dá para mim não, porque eu tenho filho e tenho

3 Por questões éticas, os nomes das entrevistadas foram substituídos por nomes fictícios. 
marido pra cuidar também”. Depois dessa casa de família, não trabalhei na casa de ninguém. Porque também eu achava um pouco humilhante, porque a pessoa que trabalha em casa de família tem que aguentar muita coisa. Assim, em termos dos filhos das donas, entendesse? É saliente, muito mimado. Nessa casa, as meninas era muito mimadas, eram daquele tipo que beliscavam, dava tapa em mim, e você não podia fazer nada, nem dizer nada. [...] $\mathrm{E}$ quando chegava uma visita a mãe e o pai ficava "eu quero isso, quero aquilo". Desse jeito, não! Fazendo você passar vergonha, era muita humilhação. Eu disse quero não!

[Diana, 25 anos]: Trabalhei antes de engravidar de Pedro [primeiro filho], antes de começar a receber o Bolsa Família, mas foi só uns três meses. Mas o patrão para pagar, misericórdia! $\mathrm{O}$ homem era tão bom de pagar que não pagou nem ao supermercado, aí foi retirado do local! Ele não pagou nem $\mathrm{o}$ aluguel do quiosque ao supermercado.

[Joelma, 25 anos]: Eu nunca trabalhei de carteira assinada, não! Trabalhei assim em casa de família. Eu tinha já minha primeira filha, fiquei uns quatro anos. Trabalhei numa casa só. Faz tempo, é estresse demais, tem que fazer tudo do jeito que a patroa quer! Era todo dia, nem no domingo tinha folga. Ela não queria nem que eu voltasse para casa para ver minha filha. E era clandestino [refere-se a não ter carteira de trabalho assinada]. Escravidão já passou! Eu vim embora... Depois de uns quatro anos assim, aí vim embora. [...] Trabalhei também num mercadinho aqui no Coque, foi agora há pouco [há cerca de dois anos]. Mas não deu certo, não! Eu saí sem justa causa. Era todo dia, não tinha folga não, de domingo a domingo. Aí também a galera não quer dar nem um sábado e nem um domingo para relaxe. Eu tenho família, tenho casa, tenho minhas filhas - na época minha filha estava com dois meses de nascida [refere-se à segunda filha]. 
O histórico de trabalho feminino no setor informal é entremeado por experiências de trabalho dos companheiros com impossibilidade de provimento familiar. $\mathrm{O}$ fato de o companheiro não conseguir prover a família está relacionado ao uso de estratégias de sobrevivência, tais como a procura por trabalhos como bicos, biscates e/ou ocupações em trabalhos subremunerados - muitas vezes chamados de ôia - por parte deles. Essa realidade não possibilita a manutenção da função de homem provedor, no entendimento tradicional que o termo simboliza $e$ está fartamente registrada em estudos sobre as condições de trabalho e geração de renda por parte de homens residentes nas periferias das regióes metropolitanas (Motta; Scott, 1983; Zaluar, 1985; Scott, 1990; Fonseca, 2004; Nascimento 2011; Sarti, 2011).

Além das trajetórias femininas de trabalho informal $e$ companheiros sem emprego, sem renda fixa $e$ com impossibilidades de provimento antes da inserção no PBF, há também relatos de companheiros que impedem mulheres de trabalhar fora da casa e experiências de inserção feminina na criminalidade e no tráfico de drogas como fonte de renda ilícita para provimento familiar. Como podemos observar:

[Cristina, 20 anos]: Quando saí da casa do pai dos meus filhos, comecei a trabalhar de fazer panfletagem para uma loja de ótica [...] Quando eu fui morar junto com Rivaldo, aí eu saí, ele não queria que eu trabalhasse.

[Eva, 29 anos]: Meu primeiro marido não trabalhava em nada e nem procurava fazer ôia! Eu que tinha que me virar para eu e para meus filhos, e para ele também. Eu ia para o sinal lavar carros, pedir uns trocado, eu entrei até em negócio de tráfico de drogas.

O detalhamento dessas trajetórias contribui para a compreensão da vivência dos postos de trabalhos informais pelas mulheres pobres, nos centros urbanos brasileiros, e da bipolarização da inserção profissional feminina, no que tange ao polo de trabalho das mulheres pobres nos setores mais 
precarizados, debatido na literatura sobre divisão sexual do trabalho (Hirata, 2010, 2002a; 2002b; Bruschini; Lombardi, 2000; Guimarães, 2010; Ávila, 2011; Melo; Di Sabbato, 2011; Ferreira, 2005).

As descrições das trajetórias das entrevistadas coincidem com dados de outras pesquisas em diversas regiões do país sobre trabalho de mulheres pobres, sobretudo entre trabalhadoras domésticas, que revelam condições de trabalho degradantes, tais como: insalubridade, altos riscos à saúde e à integridade física das trabalhadoras; jornadas de trabalho exaustivas $e$ desregulamentadas; níveis baixíssimos de remuneração; flagrantes práticas de desrespeito aos direitos humanos e do trabalho; abusos das mais diversas ordens nos níveis moral e, também, sexual (Ávila; Ferreira, 2014; Quadros, 2014; Costa et alii, 2010; Dultra; Mori, 2008; Sanches, 2009; Souza, 2002).

Contudo, na especificidade desta pesquisa com mulheres titulares do PBF, colocamos em análise os enredamentos dessas trajetórias no contexto de participação no Bolsa Família $e$ obtenção de renda permanente. No item que se segue, descreveremos relatos femininos que afirmam como a inserção na condição de titular do PBF é importante via de provimento familiar $e$ aferição de renda fixa.

\section{Bolsa Família e autonomia feminina}

A análise das trajetórias das mulheres, após a inserção no programa como titulares, aponta que esse pequeno apoio financeiro pode influenciar a possibilidade de rejeição de trabalhos inseguros, degradantes e insalubres.

O valor do benefício - variando entre $R \$ 120,00$ e $R \$ 200,00$ - é expresso como relevante pelas entrevistadas, quando comparado a situações precedentes de suas vidas e das gerações familiares antecedentes. A relevância do benefício parece não se esgotar na análise do seu valor econômico. Frente ao universo socioeconômico em que viveram ( $e$ vivem) as famílias dessas mulheres, a condição de renda mensal fixa do benefício é valorizada, mesmo levando em conta seu baixo valor. 
Verificamos que, cronologicamente, a decisão de abandonar os trabalhos degradantes ocorre em período concomitante à inserção no PBF. Nem sempre as mulheres fazem uma ligação direta entre recebimento do benefício e ocorrência da saída do trabalho ou ocupação, entretanto esse parece ser um componente que influencia a tomada de decisão, indicando a possibilidade de ampliação do poder de escolha em não aceitar qualquer posto de trabalho, em contexto de certa segurança financeira, advindo da renda do benefício.

$\mathrm{Na}$ trajetória de trabalho de Joelma, o período de inserção no Programa Bolsa Familia é simultâneo à saída do último trabalho, quando sua segunda filha tinha cinco meses. A inserção no programa aparece como esteio a partir do qual ela decide sair do trabalho que não lhe oferecia garantia trabalhista de dias de folga. No relato, Joelma enfatiza que, a partir do benefício, mesmo sem renda advinda do trabalho, consegue efetivar mudanças em sua vida:

[Joelma, 25 anos]: Para mim Bolsa Família é uma ajuda! Mudou tudo, praticamente tudo. Eu comecei a receber ela [segunda filha] estava com cinco meses de nascida. E eu tomei a iniciativa de vim morar só por causa disso, mesmo sem trabalho, porque estava recebendo o Bolsa Família.

Igualmente no relato de Joana, perante experiência de trabalho degradante, com exposição a situações humilhantes (como faxineira) e sem garantias legais de recebimento pelo trabalho exercido, escutamos possibilidade de tomada de decisão de saída do trabalho, no contexto de inserção no PBF, mesmo diante das parcas opções existentes para uma mulher, negra, com baixa escolaridade, moradora de favela, como ela própria se nomeou. Na sua trajetória de trabalho produtivo, ao sair do trabalho como cozinheira um em bar localizado na comunidade, segue para trabalho autônomo como vendedora de utensílios domésticos, produtos cosméticos e acessórios, via revista de venda por catálogo. Nos termos de Joana "o dinheiro mais certo do 
bolsa" é que permite "dá suas viravoltas" e conseguir, após saídas consecutivas de trabalhos humilhantes, tentar iniciar esse trabalho autônomo. Assim, ela posiciona suas estratégias de agência dentro dos jogos de poder possíveis e limitados pelos condicionantes estruturais (origens socioeconômicas, raça/etnia, geração, responsabilidade reprodutiva) que restringem as oportunidades de trabalho para as mulheres pobres.

No conjunto dos relatos, observamos que as mulheres almejam trabalhos mais valorizados do que as restritas opções destinadas a elas. Quando mencionam sobre projeto de vida, expressam o desejo de conquista de emprego de melhor qualidade e com garantias legais, querem empregos que ofereçam condições ocupacionais e salariais regulares a uma trabalhadora:

[Joelma, 25 anos]: [...] Queria também um trabalho. Poderia ser qualquer coisa, sendo um trabalho de carteira. Queria, porque fica mais garantido!

[Jurema, 28 anos]: [...] Queria ter meu emprego. Não tenho preferência não, porque às vezes a gente escolhe tanto... Eu só tenho preferência que fosse carteira assinada.

[Virgínia, 30 anos]: Queria estar trabalhando, eu tenho assim vontade. Mas, um trabalho que tenha hora de sair e de largar. [...] Não feito o que eu tinha que só tinha hora para entrar. Chegava cinco e meia da manhã. Não tinha hora para largar, eu, às vezes, cheguei em casa onze horas da noite, para logo cedo está lá de novo. O dia todinho em pé. Era tipo cozinha industrial, tipo negócio de marmita. De manhã, a gente chegava sem tomar café, a gente não tinha tempo de tomar café direito. Eu chegava logo cedinho para fazer coisas para o almoço, dez e meia no máximo a gente já estava servindo. Servindo assim, botando nas quentinhas, fechando, entendeu? Pagava um salário só. A gente almoçava na carreira, passei uns quatro meses ainda. Não tinha nada, era só o salário [refere-se a ser trabalho sem carteira assinada]. O dia todinho em pé, a gente só sentava para comer e a gerente ainda ficava com o olhão 
para o lado da gente, mandando a gente correr para voltar logo para trabalhar. Por isso eu não estava aguentando não, aí eu saí!

Ressaltamos que a inserção no PBF não acomoda as mulheres da busca por outras fontes de renda, como querem fazer crer os propagadores do discurso do efeito preguiça. Segundo Oliveira e Soares (2013), a expressão efeito preguiça relaciona-se com crítica que enfatiza que um dos efeitos de outorgar um benefício monetário para as famílias de renda baixa pode ser a acomodação da busca por trabalho, entre seus membros. Os relatos das mulheres do Coque evidenciam o contrário, mostram busca de melhoria das condições de trabalho e emprego que possa garantir direitos, como por exemplo, direito a preservação da saúde da trabalhadora e remuneração regular, possibilidades de sair do trabalho clandestino, como elas nomeiam.

$\mathrm{O}$ que encontramos foram estratégias femininas, a partir da condição de titularidade do PBF, que possibilitam, em alguma medida, condição de rejeição aos trabalhos mais desvalorizados e/ou sub-remunerados e ampliação de possibilidade de procura por trabalho melhor remunerado, valorizado e/ou empregos formais.

Em oposição ao discurso que interliga disponibilização de benefícios monetários e efeito preguiça, as experiências relatadas contribuem para observarmos possibilidade de agência, em decorrência de ação feminina, incluída no hall dos menos poderosos, como aponta Sherry Ortner (2006a, 2006b, 2005). O recebimento de renda fixa advinda do $\mathrm{PBF}$ proporciona formas de agir que, em alguma medida, desafiam e impõem resistência à ocupação de postos de trabalho não valorizados, tentando também reconfigurar o percurso de trabalho feminino dentro das gerações familiares.

Ao compreender o empoderamento como processo que se concretiza no intercruzamento das dimensões de recursos, agência e realizações (Kabeer, 1999; 2005), que busca subverter relações de poder opressoras e toma lugar entre contextos institucionais, 
materiais e discursivos (León, 2001, 2000; Sardenberg, 2010, 2006), a ampliação de possibilidades de fazer escolhas sobre outras oportunidades ocupacionais pode ser considerada um importante indício de empoderamento dessas mulheres na esfera produtiva. Assim, a aglutinação do acesso a recurso financeiro permanente (advindos da inserção em programas de transferência de renda com titularidade feminina - Bolsa Família) incide sobre agência (com ampliação de escolhas ocupacionais) e promove realizações (potencialidades de transformações no poder decisório dentro da esfera produtiva).

Obviamente, compreendemos que o empoderamento está relacionado a ações e mobilizações coletivas dentro de um processo político (León, 2001, 2000); processos de transformação das estruturas $e$ instituições que perpetuam as desigualdades de gênero (Sardenberg, 2010, 2006). Dessa maneira, a mensuração sobre melhoria na agência e mudanças de vida das mulheres, deve contemplar mudanças coletivas e reestruturações das desigualdades de gênero (Kabeer, 1999) que não parecem existir no cenário atual.

Os processos de empoderamento relacionados ao âmbito sociocultural (Kabeer, 1999) compreendem a aquisição do controle sobre decisões de vida, logram a habilidade de fazer coisas $e$ definir suas agendas (León, 2000; 2001) e devem promover análises que contemplem a intersecção entre as dimensões pessoais, sociais, econômicas e políticas do empoderamento, mesmo quando a situação estrutural parece pouco alterada.

Essa dimensão pessoal tem sido utilizada no desenvolvimento de indicadores de mensuração para promover a manutenção do status quo (Kabeer, 1999), em estatísticas de organizações multilaterais e bancos que promovem $e$ financiam projetos e programas de desenvolvimento em países do sul. A análise ora empreendida, não se encaminha nessa direção. Visibilizamos trajetórias que exaltam uma dimensão histórica, ao mesmo tempo que apontam as limitações estruturais, as alternativas limitadas e valorizam as possibilidades de agência nestas situações. 
No contexto sociocultural de exclusão e opressões de gênero (com intersecções de raça/etnia e condição social), vividos por essas mulheres, ter maior oportunidade para rejeitar trabalhos degradantes ou vexatórios $e$ ampliar busca por trabalhos mais valorizados pode ser analisado como ampliação de escolhas e realizações consideradas como dimensões importantes de autonomia feminina.

Ao fazer uso do conceito de autonomia, rejeitamos qualquer posicionamento relacionado com autossuficiência e autogoverno, tal como formulado dentro do clássico discurso do liberalismo moderno, na prerrogativa de autonomia como ideal pessoal, segundo a qual indivíduos são autores de suas próprias vidas $e$ são capazes de escrever a história de sua própria vida (Di Stefano, 1996). Aqui, a compreensão sobre autonomia engloba espaços de lutas e conquistas das mulheres dentro das opressões históricas de gênero, bem como, é também usada na defesa de que a autonomia, a nível individual, está intrinsecamente relacionada com as relações sociais, políticas e econômicas.

Obviamente, a focalização feminina, em termos de titularidade, nos programas de transferência de renda, segue também por percursos da abordagem da eficiência e do bem estar, implementadas dentro das diversas políticas, programas e projetos de desenvolvimento para as mulheres nos países do "terceiro mundo" (Moser, 1989; Buvinic, 1986; Kabeer, 2003), que operavam (e operam) para reforço das atribuições femininas restritas as funções de cuidado reprodutivo $e$ uso do tempo e trabalho não remunerado feminino, no bojo de políticas neoliberais $e$ diminuição de orçamentos com políticas sociais.

As abordagens de eficiência e bem estar (Moser, 1989) se distanciam, no debate de gênero e desenvolvimento, da perspectiva de empoderamento como caminho de transformação das relações hierárquicas de poder, busca por autonomia, estímulos à organização coletiva, mobilização de resistência contra a dominação masculina, no histórico cenário de ideologia patriarcal (León, 2000, 2001; Kabeer, 1999, 2003, 2005; Sardenberg, 2012, 2010). 
Contudo, na ação e na interação da vida cotidiana, atravessada por essa titularidade, as mulheres mostram também como podem usar intenções políticas adversas a seu favor, no cenário de desigualdades de gênero (Ortner, 1990) e mobilizar sítios de ações que podem exercer algum tipo de influência sobre a maneira como os acontecimentos se desenrolam (Ortner, 2006b).

No contexto de vida cotidiana, as mobilizações femininas nos mostram como as mulheres, titulares do PBF, podem delinear canais de entrecruzamento das diferentes perspectivas da focalização feminina, adicionando conotações particulares a partir do contexto sociocultural vivido.

A reflexão sobre o processo de autonomia feminina precisa incluir outros elementos. Dentre eles, nos parece fundamental a discussão sobre a temporalidade do benefício do PBF (condicionado a faixa etária das crianças e adolescentes na família) e relatos sobre ausência e/ou ineficiência de políticas de formação e qualificação profissional que viabilizem maior acesso ao mercado de trabalho formal, a partir de críticas tecidas pelas próprias mulheres. É o que abordaremos nesta última seção.

\section{Bolsa Familia: qualificação profissional entre mulheres titulares}

No diálogo com as mulheres titulares do PBF acompanhadas pela pesquisa, observamos também questionamento sobre a temporalidade do benefício condicionado à faixa etária das crianças e adolescentes na família, bem como ao foco do PBF apenas nos/nas filhos/filhas. Os relatos de Eva e Joana exemplificam críticas em relação às restrições de políticas de empregos para as mulheres, à temporalidade do benefício e às relações desvantajosas de vinculação com número de filhos $e$ inserção no PBF:

[Eva, 29 anos]: [...] O governo pensa que dar Bolsa Família, Bolsa Escola, pensa que é tudo! Que nem eu digo direto era para eles dar era emprego a gente, e não bolsa escola, bolsa família. Aí diz "Estou fazendo isso por causa do bolsa escola, aí é para cuidar dos filhos". E eles ficam com os 
filhos? Eles estão no dia a dia com os filhos? Eles estão pensando que Bolsa Escola e Bolsa Família é tudo na vida da pessoa? É não! [...] Achava melhor dar um emprego, é mais digno, saber que a gente estava suando e estava ganhando o dinheiro da gente, a gente ia fazer um futuro. Porque bolsa escola o menino chega aos 14 anos a gente perde, corta a bolsa. Bolsa família, a mesma coisa: os meninos estão grandes, a gente deixa de receber. Aí como é que a pessoa vai viver? Mas com emprego, não! Eles dando emprego era outra coisa, a gente ia ter os direitos da gente. Eu achava melhor eles pegar esse dinheiro e investir em emprego, cursos.

[Joana, 29 anos]: Eu acho que isso é ilusão da gente dizer assim, ter menino confiando em bolsa família, isso não é futuro. Porque dinheiro é uma coisa, para pessoa educar, criar, é outra coisa. [...] Agora eu digo uma coisa, eu conheço gente assim, que cada vez que o filho vai ficando maior, aí para o bolsa família não acabar, vai tendo filho pequeno. Isso não existe, vai se encher de filho? E se disser: "agora acabou o dinheiro". De repente pode passar, a gente bloqueou os cartões de todo mundo, todo mundo vai gritar, fazer zoada lá, "eu quero meu dinheiro", mas vai estar tudo bloqueado.

Ao enfatizarem o caráter passageiro do programa, Eva $e$ Joana apontam para a falta de efetividade do benefício em resolver os problemas financeiros das famílias pobres. Considerado mais como uma ajuda e não como uma medida que traria a solução dos problemas de renda, garantindo a participação no mercado de trabalho e promovendo a dignidade da família e o acesso a direitos.

As mulheres chamaram a atenção para a sobrecarga do papel de cuidadora da mulher pobre que, em geral, é desprovida de serviços públicos de qualidade (para elas mesmas e seus filhos - saúde, educação, habitação) e alijada de perspectiva de vida que transpasse a destinação unívoca da maternidade. Seus relatos reforçam a procura por projetos para maior acesso ao mercado de 
trabalho, mesmo em face de políticas sociais que persistem em concentrar $\mathrm{o}$ foco de ações na dualidade mulher/pobre maternidade/casa (Mariano; Carloto 2013, 2009).

Na cidade do Recife (Pernambuco), informe sobre parceria entre Secretaria de Assistência Social e Secretaria de Educação menciona oferta de cursos de qualificação profissional (entre outros, nas áreas de higiene e beleza, vestuário, artesanato, construção civil, arte, idiomas, alimentação, turismo), com relatos de cotas de vagas reservadas para titulares e beneficiários do Programa Bolsa Escola e Bolsa Família, entre outros beneficiários de programas sociais. ${ }^{4}$

Entretanto, as entrevistadas apontam ausência de políticas integradas de emprego e qualificação profissional, o que diretamente impõe obstáculos à solidificação do processo de autonomia feminina. A maioria das titulares não faz nenhuma menção a cursos de qualificação, desconhecendo esse tipo de ação direcionada para as mesmas. Apenas Eva relata sobre a oferta de cursos de qualificação profissional, no entanto, tece críticas em relação ao tipo de cursos ofertados e à falta de direcionamento para contratação de trabalho:

[Eva, 29 anos]: Eles dão cursos, mas você tem que ter passagem para ir... E tem vez que eles dão, mas o curso que eles dão só é para falar, não pratica... Eu tenho dois cursos... Curso de cabeleireiro e de culinária... Nem o de culinária, nem o de cabeleireiro teve prática... Seis meses de curso... Sem experiência, sem nada... Eu tenho um irmão que fez curso de garçom... Fez curso de pedreiro, $e$ cadê emprego? Está aí desempregado. Era para empregar a gente, teve esse negócio do shopping [refere-se a uma obra de construção de shopping construído ao lado da comunidade do Coque, que desapropriou algumas áreas da comunidade]. Teve esse negócio da Copa [refere-se à

${ }^{4}$ Informação acessada em <:http://www2.recife.pe.gov.br/abertas-12-mil-vagaspara-cursos-profissionalizantes-no-recife/>. No entanto, não encontramos disponível publicamente informação sobre cursos (oferta, níveis de qualificação, periodicidade) e particularidade relativa aos beneficiários do PBF. 
construção da Arena Pernambuco - Estádio de Futebol, construído em virtude da Copa das Confederações (2013) e Copa do Mundo (2014)]. Cadê? Nada! O que é que adianta? O governo dá curso de graça! Ele dá o curso de graça, mas cadê a prática, porque a gente só aprende se praticar e tem que ter emprego para a gente trabalhar.

A descrição acerca das desigualdades estruturais das relações de gênero e classe, na qualidade de titulares do PBF, reforça debate de que as políticas de superação do ciclo de pobreza feminina têm que necessariamente perpassar por questões de acesso, permanência e condições da participação no mercado de trabalho, rompendo as barreiras do aprisionamento da dicotomia mulher-mãe.

Incentivos e ampliação de cursos profissionalizantes, para além das típicas formações nas áreas compreendidas como femininas (culinária, higiene, limpeza...), condições de acesso à qualificação profissional e integração com políticas de emprego deveriam ser ações efetivadas para mulheres que participam de programa de transferência de renda com titularidade feminina. Assim, certamente estaríamos em percurso de solidificação de empoderamento feminino para além da temporalidade de uma política de transferência de renda e das abordagens da eficiência e bem estar nos projetos e políticas de desenvolvimento.

Ao nomear a relação desvantajosa estabelecida entre aumento do número de filhos e a continuidade da mulher no PBF, os relatos ratificam a limitação de tomar o feminino apenas em sua função reprodutiva e urgência de políticas de desenvolvimento que integrem as mulheres pobres ao mercado de trabalho em postos mais qualificados e com maior garantia de direitos trabalhistas. Certamente a concretização do PBF como política de gênero, e não apenas como política de redução da pobreza, transformaria a visualização de futuro cogitada pelas mulheres.

Nas trajetórias relatadas, com histórico de ocupação em trabalhos informais, subremunerados e desvalorizados, as mulheres mostraram que a obtenção de renda permanente do PBF amplia a possibilidade de rejeição a essas ocupações, com 
repercussão na prospecção de empregos e trabalhos mais valorizados e, consequentemente, ampliação de autonomia, no processo de empoderamento feminino. No entanto, o debate sobre temporalidade do benefício do PBF também aponta ausência de políticas integradas de emprego e qualificação profissional, o que impõe obstáculos à solidificação do processo de autonomia feminina.

Apesar de algumas políticas estarem sendo dirigidas às mulheres, necessariamente não está sendo contemplada a perspectiva de gênero, o que possibilita restrita condição de ruptura das relações hierárquicas de poder (Nanes, 2014; Mariano; Carloto, 2013; 2009; Bandeira, 2005; Farah, 2004; Camurça, 2002).

\section{Considerações finais}

Neste artigo, descrevemos as repercussões da titularidade feminina do PBF nas trajetórias produtivas de mulheres, residentes na comunidade do Coque (Recife/PE). Argumentamos que a aglutinação do acesso aos recursos financeiros (advindos da inserção no $\mathrm{PBF}$ ) e ações de agência feminina (com ampliação de escolhas ocupacionais) repercute em realizações/transformações na vida dessas mulheres e suas experiências no âmbito do trabalho produtivo. A ampliação das margens de agência na rejeição de trabalhos vividos como vexatórios e degradantes constitui importante esteio no percurso de empoderamento feminino.

Contudo, na medida em que os relatos também problematizam a limitação de tomar o feminino apenas em sua função reprodutiva $e$ ineficiência e/ou ausência de políticas de inserção e qualificação profissional, reiteramos a perspectiva restritiva da titularidade feminina no Programa Bolsa Família, como uma via de instrumentalização da mulher para fins de combate à pobreza.

Realçamos como essas limitações fragilizam a potencialidade de solidificação dos processos de autonomia na esfera produtiva, mobilizados no hall de ação das mulheres titulares em busca de 
empregos e superação de ocupação de postos de trabalhos informais, no ciclo de pobreza intrageracional; bem como, dificultam rompimento das tradicionais atribuições da mulher com o cuidado com filhos/casa, especialmente em grupos de mulheres em condição de pobreza. Essa potencialidade que conseguimos encontrar nos depoimentos das entrevistadas também não subsumiu outras problemáticas encontradas na vida dessas mulheres tais como as restrições impostas ao usufruto de direitos sexuais e reprodutivos, a ausência de projetos relacionados a esferas de poder, etc, mas contribui para o processo de empoderamento.

A avaliação de possibilidades de empoderamento, valorizaram as trajetórias pessoais sem deixar de lado a dimensão coletiva e a perspectiva de transformação das relações sociais. Ao colocar em evidência a agência feminina, não deixamos de lado a situação de subordinação estrutural dessas mulheres, ao contrário, procuramos evidenciar como elas constroem estratégias que lhes permitam alguma melhoria de vida.

Sabemos que tal melhoria não se efetivará como uma mudança para a igualdade de gênero, caso não seja acompanhada por medidas programáticas, de caráter macrossocial e macroeconômico que possibilitem reconfigurações desse cenário, mas os exemplos de agência das mulheres pobres que encontramos nesta pesquisa podem possibilitar a formação de frestas ou fendas que tentam romper os marcadores de subordinação que lhes são destinados.

Ao considerar que o PBF está inserido em um conjunto de programas de transferência de renda que têm sido implementados na América Latina, como um dos componentes das políticas públicas para o desenvolvimento social e que apresentam uma característica comum de destinar a titularidade do benefício às mulheres, é preciso fomentar análises que debatam essa titularidade feminina tendo como perspectiva a igualdade de gênero.

Nesse sentido, é necessário investigar a repercussão nos arranjos da vida cotidiana das mulheres, que em geral não 
aparece na análise e no debate sobre o PBF, mas que faz parte dos processos vividos pelas titulares. Só assim será possível reunir informações para propor modificações estruturais no desenho do PBF e suas políticas integrativas, a fim de superar proposições que justificam a titularidade feminina no PBF, no hall de uma concepção de família profundamente marcada pela hierárquica divisão sexual do trabalho.

Apesar de o PBF não ter sido desenhado como uma política de gênero, afirmamos que a titularidade feminina do programa deve ser avaliada pelo aporte do debate sobre políticas de gênero $e$ desenvolvimento. O PBF não é apenas um programa de transferência de renda destinado às famílias em condição de pobreza ou extrema pobreza, é um programa que legitima a titularidade feminina, dentro do espectro da focalização feminina, que engloba um conjunto de reflexões e críticas mobilizado dentro do movimento feminista (em níveis internacional, regional $e$ nacional), cuja articulação dentro de agências $e$ instituições de desenvolvimento tem sido reapropriada de forma desvantajosa para as mulheres e destoante das perspectivas de igualdade de gênero fomentadas pela luta feminista.

Essa reapropriação tem norteado proposições governamentais e políticas sociais restritivas à promoção dos direitos humanos das mulheres. É urgente fomentar o debate sobre a focalização feminina no PBF a partir da perspectiva da igualdade de gênero $e$ da constituição de políticas de desenvolvimento que contemplem a mulher como sujeito de direitos.

\section{Referências bibliográficas}

ÁVILA, Maria Betânia. Reflexões sobre as desigualdades de gênero e raça no mercado de trabalho. In: FunDAÇÃo Alexandre de Gusmão (org.). Autonomia econômica e empoderamento da mulher. textos acadêmicos. Brasília, Fundação Alexandre de Gusmão, 2011, vol. 1. cap. 11, pp.187-206. 
ÁvILA Maria Betânia; FERREIRA Verônica. Trabalho produtivo $e$ reprodutivo no cotidiano das mulheres brasileiras. In: ÁvILA, Maria Betânia; FERREIRA, Verônica (org.). Trabalho remunerado e trabalho doméstico no cotidiano das mulheres. Recife, SOS corpo, 2014, pp.13-51.

BANDEIRA, Lourdes. Brasil: fortalecimento da secretaria especial de políticas para as mulheres para avançar na transversalização da perspectiva de gênero nas políticas públicas. In: MELO, Hildete; BANDEIRA, Lourdes. A pobreza e as políticas de Gênero no Brasil. Santiago de Chile, CEPAL, Série Mujer y Desarrollo, nº 66, 2005, pp.43-76.

BRASIL. Ministério do Desenvolvimento Social e Combate à Fome. Secretaria Nacional de Renda de Cidadania. Portaria GM/MDS n ${ }^{\circ}$ 246, de 20 de maio de 2005. Aprova os instrumentos necessários à formalização da adesão dos municípios ao Programa Bolsa Familia, à designação dos gestores municipais do Programa e à informação sobre sua instância local de controle social, e define o procedimento de adesão dos entes locais do referido Programa. [http://www.mds.gov.br/sobreoministerio/legislacao/bolsafamilia/portar ias/2005/Portaria\%20GM\%20MDS\%20246\%2020-5-05.pdf - acesso em: 15 jun. 2015].

BRUSCHINI, Cristina; LOMBARDI, Maria Rosa. A bipolaridade do trabalho feminino no Brasil contemporâneo. Cadernos de Pesquisa (110), 2000, pp.67-104.

BuvINIC, Mayra. Projects for Women in the Third World: Explaining their Misbehavior. World Development (5), 1986, pp.653-664.

CAMURÇA, Silva. Sobre o problema das desigualdades de gênero no desenvolvimento e para a democracia. In: BUARQUE, Cristina et alii. Perspectivas de Gênero: Debates e questóes para as ONGs. Recife, GT Gênero. Plataforma de Contrapartes Novib/SOS CORPO Gênero e Cidadania, 2002, pp.164-175.

COSTA, Albertina et alii. Divisão sexual do trabalho e emprego doméstico no Brasil. In: (org.). Divisão sexual do trabalho, estado e crise do capitalismo. Recife, SOS Corpo, 2010, pp.115-170.

Di STEFANO, Christin. Problemas e incomodidades a propósito de la autonomia: algunas consideraciones desde el feminismo. In: 
Castells, Carmem (org.) Perspectivas feministas en teoría política. Barcelona, Paidós, 1996, pp.53-78.

DULTRA, Eneida; MoRI, Natalia. Trabalhadoras domésticas em luta: Direitos, igualdade e reconhecimento. Brasília, CFEMEA, ACDI/CIDA, 2008.

FARAH, Marta. Políticas Públicas e Gênero. In: GodinHO, Tatau; SILVEIRA, Maria Lúcia (org.). Políticas Públicas e Igualdade de Gênero. São Paulo, Coordenadoria Especial da Mulher, 2004, Cap. 9, pp.127142.

FERREIRA, Verônica. O novo e o velho no trabalho das mulheres. In. SiLVA, Carmem; ÁvilA, Maria Betânia; FerREIRA, Verônica (org.). Mulher e trabalho. Recife, SOS Corpo e Secretaria Nacional Sobre a Mulher Trabalhadora da CUT, 2005.

FONSECA, Claudia. Familia, fofoca e honra: Etnografia de relações de gênero e violência em grupos populares. 2.ed. Porto Alegre, Ed. UFRGS, 2004.

GUIMARÃES, Iracema. Gênero e trabalho desafios da intervenção nas atividades informais. In: ALVES, Ivia et alii (org.). Travessias de gênero na perspectiva feminista. Salvador, EDUFBA/NEIM, 2010, pp.103128.

HIRATA, Helena. Reorganização da produção e transformação do trabalho; uma nova divisão sexual? In: BRUSCHINI, Cristina; Unbehaum, Sandra (org.). Gênero, Democracia e Sociedade. São Paulo, FCC/ Ed 34, 2002a, pp.341-355.

. Globalização e Divisão Sexual do Trabalho. cadernos pagu (18), Campinas-SP, Núcleo de Estudos de Gênero-Pagu/Unicamp, 2002b, pp.139-156.

Emprego, responsabilidades familiares e obstáculos socioculturais à igualdade de gênero na economia. Revista do Observatório Brasil da Igualdade de Gênero, Brasília, Secretaria de Políticas para as Mulheres da Presidência da República, dez 2010, pp.45-50.

KABEER, Naila. Resources, agency, achievements: reflections on the measurement of women's empowerment. Development and Change (3), International Institute of Social Sciences, 1999, pp.435-464. 
. Reversed Realities: gender hierarchies in development. London, Verso, 2003.

. Gender equality and women's empowerment: a critical analysis of the third millennium development goals. Gender and Development (1), Grã Bretanha, OXFAM, mar 2005, pp.13-24.

LAVINAS, Lena; CoBO, Barbara; VeIGA, Aline. Bolsa Família: impacto das transferências de renda sobre a autonomia das mulheres pobres $e$ as relações de gênero. Revista Latinoamericana de Población (10), Asociación Latinoamericana de Población, Jan/Jun 2012, pp.31-56.

LEÓN, Magdalena. Empoderamiento: relaciones de las mujeres com el poder. Revista Estudos Feministas (2), Florianópolis, Universidade Federal de Santa Catarina, 2000, pp.191-205.

. El empoderamiento de las mujeres: Encuentro del primer y tercer mundos en los estudios de gênero. Revista de Estudios de Género (13), La Ventana, 2001, pp.94-116.

MARIANO, Silvana; CARLOTO, Cássia. Gênero e Combate a Pobreza: Programa Bolsa Família. Revista Estudos Feministas (17), Florianópolis, Universidade Federal de Santa Catarina, 2009, pp.901908.

- Aspectos Diferenciais da Inserção de Mulheres Negras no Programa Bolsa Família. Sociedade e Estado (28), Brasília, UnB, 2013, pp.343-417.

Melo, Hildete; Di SABBATO, Alberto. Divisão sexual do trabalho e pobreza. In: Fundação Alexandre de Gusmão. Autonomia econômica e empoderamento da mulher. textos acadêmicos. Brasília, Cap. 4, 2011, pp.53-72.

Moore, Henrietta. Antropología y Feminismo. 4. ed. Madri, Ediciones Cátedra; Universitat de Valência; Instituto de La Mujer, 2004.

Moser, Caroline. Gender planning in the Third world: meeting practical and strategic gender needs. World Development (11), 1989, pp.17991825.

MotTA, Roberto; ScotT, Parry (org.). Sobrevivência e Fontes de Renda: estratégias das famílias de baixa renda no Recife. Recife, Massangana, 1983. 
NANES, Giselle. Ele ainda canta de galo: etnografando homens pobres no domínio da casa. Dissertação (Mestrado em Antropologia), Universidade Federal de Pernambuco, 2010.

NASCIMENTO, Pedro. Não-provedores: homens, mulheres e desemprego em uma "Invasão" em Camaragibe/PE. In: NASCIMENTO, Pedro; RIOS, Luís Felipe (org.). Gênero, saúde e práticas profissionais. Recife, Editora Universitária UFPE, 2011, pp.183-212.

OLIVEIRA, Luís; SOARES, Sergei. "Efeito preguiça" em programas de transferência de renda? In: CAMPELLO, Tereza; NERI, Marcelo. Programa Bolsa Familia: uma década de inclusão e cidadania. Brasília, IPEA, 2013, Cap. 22, pp.341-358.

ORTNER, Sherry. Gender hegemonies. Cultural Critique (14), Minneapolis, The University of Minnesota Press, 1990, pp.35-80.

. Subjectivity and cultural critique. Anthropological Theory (1), mar 2005, pp.31-52.

. Updating Practice Theory. In: ORTNER, Sherry. Anthropology and Social Theory. Culture, Power and The Acting Subject. London, Duke University Press, 2006a, pp.1-19.

. Power and Projects: Reflections on Agency. In: ORTNER, Sherry Anthropology and Social Theory. Culture, Power and The Acting Subject. London, Duke University Press, 2006b, pp.129-154.

QuADROS, Marion Teodósio. Desenvolvimento, Sexualidade de Mulheres Jovens, Políticas de Educação e Práticas Educativas: entre ausências, silenciamentos e invisibilizações. Revista Anthropológicas (25-2), Recife, Programa de Pós-Graduação em Antropologia da UFPE, 2014, pp.175-206.

RABELO, Maria Mercedes. Redistribuição e Reconhecimento de cidadania através do Programa Bolsa Família (PBF). Ensaios FEE (Impresso), vol. 34, 2013, pp.57-90.

REGO, Walquiria. Aspectos teóricos das políticas de cidadania: uma aproximação ao Bolsa Família. Lua Nova (73), São Paulo, Centro de Estudos de Cultura Contemporânea da USP, 2008, pp.147-185.

. Política de cidadania no governo Lula: ações de transferência estatal de renda: o caso do Bolsa Família. Temas y Debates (20), 
Rosário, Facultad de Ciencia Política y Relaciones Internacionales de la Universidad Nacional de Rosario, out 2010, pp.141-155.

. Liberdade, Dinheiro e Autonomia: o Caso da Bolsa Família Política \& Trabalho, Revista de Ciências Sociais- Política e Trabalho (38), João Pessoa, Programa de Pós-Graduação em Sociologia da UFPB, abril 2013, pp.21-42.

; PINZANI, Alessandro. Vozes do Bolsa Família: autonomia, dinheiro e cidadania. São Paulo, Editora UNESP, 2013.

SANCHES, Maria Aparecida. Trabalho doméstico: desafios para o trabalho decente. Revista Estudos Feministas (3), Florianópolis, Universidade Federal de Santa Catarina, setembro-dezembro 2009, pp.879-888.

SARDENBERG, Cecilia. Conceituando "Empoderamento" na Perspectiva Feminista. In: I Seminário Internacional: Trilhas do Empoderamento de Mulheres - Projeto TEMPO. NEIM/UFBA, Salvador, Junho de 2006

[https://repositorio.ufba.br/ri/bitstream/ri/6848/1/Conceituando\%20E mpoderamento\%20na\%20Perspectiva\%20Feminista.pdf - acesso em: dez. 2013].

. Women's Empowerment in Brazil: Tensions in Discourse and Practice. Development (53), Cambridge, dec 2010, pp.232-238.

. Negotiating Culture in the Promotion of Gender Equality and Women s Empowerment in Latin America. IDS Working Paper, 2012, pp.03-44.

SARTI, Cynthia. A familia como espelho: um estudo sobre a moral dos pobres. 7. ed. São Paulo, Cortez, 2011.

SORJ, Bila; FONTES, Adriana. Políticas públicas e a articulação entre trabalho e família: comparações inter-regionais. In: FARIA, Nalu; MORENO, Renata (org.). Cuidado, trabalho e autonomia das mulheres. São Paulo, Sempre Viva Organização Feminista, 2010, Cap. 3, pp.57-74.

SuAREZ, Mireya; LiBARDONI, Marlene. O Impacto do Programa Bolsa Familia: Mudanças e Continuidades na Condição Social das Mulheres. In: VAITSMAN, Jeni; PAES-SOUSA, Rômulo (org.). Avaliação de políticas e programas do MDS - resultados: Bolsa Família e 
Assistência Social. Brasília-DF, MDS; SAGI, 2007, Cap. 4, pp.119162.

TEBET, Mani. Percepções de gênero entre casais beneficiários do Programa Bolsa Família. DILEMAS: Revista de Estudos de Conflito e Controle Social (2), Abr/Mai/Jun 2012, pp.295-334.

ZALUAR, Alba. A Máquina e Revolta: organizações populares e o significado da pobreza. São Paulo, Brasiliense, 1985. 